\title{
Ontogenetic vertical distribution patterns in small copepods: field observations and model predictions
}

\author{
Josefin Titelman*, Øyvind Fiksen \\ Department of Biology, University of Bergen, PO Box 7800, 5020 Bergen, Norway
}

\begin{abstract}
We investigated fine-scale $(5 \mathrm{~m}, 4 \mathrm{~h})$ species- and stage-specific (N1 to C6) distributions of common copepods at an anchor station in a Swedish fjord during two $24 \mathrm{~h}$ periods in October 1997. Generally, both calanoid and cyclopoid nauplii were found near the surface, while copepodids stayed deeper in the water column. No diurnal migration was observed. To analyze the observed distributions, we combined mechanistic models of predation risk from fish and copepods, formulations of temperature-dependent growth and a habitat optimization model, maximizing expected lifetime reproductive output. Motility pattern has implications for encounter rates with copepod predators, and therefore affected optimal vertical positioning in the model. By applying species- and stagespecific motility, and accounting for the ambient copepod predator field, we computed depth profiles of the mortality risk for the observed field situation. Predicted diel and ontogenetic vertical distribution patterns for various levels of fish concentrations were compared with observed distributions, and much of the patterns in the field were explained by the model. While the risk of fish predation governs the deeper habitat selection of the larger copepodids, the risk of copepod predation is probably more important for nauplii and small copepods. In addition, the vertically homogeneous growth profile and dense layers of copepod predators may wipe out potential benefits of diurnal migration.
\end{abstract}

KEY WORDS: Nauplii · Oithona spp. Habitat optimization · Predation risk · Encounter $\cdot$ Behavior

\section{INTRODUCTION}

The pelagic realm provides few physical refuges from predators. However, vulnerable zooplankton may reduce predation risk from visual predators by resting at depths where ambient light levels limit search efficiency (Zaret \& Suffern 1976, Aksnes \& Giske 1993). If subject to rheotactic predators, such as larger copepodids, zooplankters may limit predation risk by adopting a 'silent' motility pattern that minimizes predator detection and encounter rates (cf. Tiselius et al. 1997). Alternatively, plankters may behave according to the concept that 'an enemy's enemy is a friend', and reside near the surface when larger invertebrate predators face high risk from fish, and descend at night when their predators come to the surface (Ohman et al. 1983). Migration patterns vary with size; large zooplankters are very visible to fish and may therefore leave the surface during the day to reduce predation risk (De Robertis et al. 2000, De Robertis 2002), while small zooplankton are less visible but more susceptible to predation from invertebrates (e.g. Landry \& Fagerness 1988).

Theoretical studies suggest that younger stages maximize fitness by selecting habitats supporting high growth rates, even when risk is high, in order to minimize lifetime exposure to predators (Fiksen \& Giske 1995). Later stages with higher reproductive value should instead pay more attention to survival (Clark 1994). In addition, zooplankton habitat selection is flexible, and may change with the abundance of dominant predator (Ohman 1990, Frost \& Bollens 1992, Loose \& Dawidowicz 1994). If growth is maximized near the surface, small or juvenile copepods may maximize their fitness by staying there for 2 reasons; viz. (1) the large and potentially dangerous zooplankton leave the surface waters during daytime, and (2) faster growth allows prey to grow out of the predation size 
window of many larger zooplankters more quickly (Fiksen \& Giske 1995, Fiksen 1997).

There has been a considerable research effort describing and quantifying the behavior of zooplankton, and small-scale predator-prey interactions in the laboratory (e.g. Tiselius \& Jonsson 1990, Paffenhöfer et al. 1996, Titelman \& Kiørboe 2003a). Many copepods are omnivorous and feed effectively on younger developmental stages (e.g. Landry \& Fagerness 1988, Sell et al. 2001). Recently, theoretical and experimental studies have demonstrated how nauplii and copepodid prey may influence detectability and encounter rates with tactile predators through their motility patterns (e.g. Tiselius et al. 1997, Kiørboe et al. 1999, Caparroy et al. 2000, Titelman 2001). Prey size also has direct and indirect influences on predation by both copepods and fish. Size affects both the magnitude of the hydrodynamic signals generated by motility and signal perception (Kiørboe \& Visser 1999, Kiørboe et al. 1999, Titelman \& Kiørboe 2003b). In addition, escape velocity often increases with size (Mauchline 1998, Titelman \& Kiørboe 2003b). Prey may also simply outgrow the predators' prey-size spectrum. When compared to similarly sized copepodids, nauplii are generally more susceptible to copepod predation (e.g. Landry \& Fagerness 1988). The susceptibility to visual predators typically increases with prey size (Brooks \& Dodson 1965).

It is not yet known how well the small-scale mechanisms involved in motility, signal perception and generation, and predator-prey interactions that we observe in the laboratory scale up to field situations and the distribution of zooplankters. Unfortunately, of the many reports of copepod vertical distributions, only few consider naupliar stages, and even fewer separate nauplii into species or stages (e.g. Lagadeuc et al. 1997, Durbin et al. 2000, Incze et al. 2001). This contrasts with the fact that nauplii make up the numerical bulk of copepods. One may hypothesize that speciesor stage-specific differences in behavior (e.g. Titelman \& Kiørboe 2003a,b) are also reflected in field distributions. Here we attempt a step towards exploring this by examining the distribution of nauplii and small copepodids in a Swedish fjord.

The vertical distribution of all stages (N1 to C6) of common species was recorded during $2 \mathrm{~d}$ of intense sampling. We modeled growth and predation rates from the physical and biological environment observed in the fjord. We implemented the motility patterns of each stage and species into mechanistic models of both copepod and fish predator-prey interactions. Then, by use of a dynamic optimization model, we calculated the sequence of habitat selections that maximize reproductive value for all size categories, in increments of $1 \mathrm{~h}$. Finally, we compared the model results with the field observations.

\section{MATERIALS AND METHODS}

Sampling scheme. We sampled at an anchor station $\left(58^{\circ} 16.00^{\prime} \mathrm{N}, 11^{\circ} 28.34^{\prime} \mathrm{E}\right.$, depth $\left.\sim 60 \mathrm{~m}\right)$ in Gullmarsfjorden, western Sweden, during two $24 \mathrm{~h}$ periods between 26 and 29 September 1997. Sampling was conducted at $4 \mathrm{~h}$ intervals, starting at 09:30 h on 26 and 28 September and ending after the 09:30 h sampling the following day. Bottle (5 1 Hydrobios PWS) samples for zooplankton were collected at $5 \mathrm{~m}$ depth intervals between the surface and $55 \mathrm{~m}$, simultaneously with CTD (Neil Brown MK III) and relative fluorescence measurements (Sea Tech). Additional CTD casts were carried out at $2 \mathrm{~h}$ intervals. Surface light was measured nearby at Kristineberg Marine Research Station, Fiskebäckskil. Profiles of chlorophyll a (chl a) were obtained at the 13:30 and 01:30 samplings. Water samples for chl a were GF/F filtered, the filters extracted in alcohol and the extract measured on a fluorometer (Turner Designs AU-10).

Zooplankton. Zooplankton were collected from the bottle samples by screening the water through a $40 \mu \mathrm{m}$ mesh, whereupon the plankton were preserved in $4 \%$ formalin. We considered 12 taxa, of which all the calanoids and oithonids were identified to stage while Coryceaus anglicus, Oncaea borealis, and Microsetella norvegica were only separated into nauplii or copepodids. Nauplii were identified to species and stage where possible under an inverted microscope (Leica DMIL equipped with a relief segment), following Oberg (1906) and Ogilvie (1953) for the calanoids, Lovegrove (1956) for M. norvegica, Haq (1965), Oberg (1906), Gibbons \& Ogilvie (1933) and Lovegrove (1956) for Oithona similis and Oithona nana, Gibson \& Grice (1978) for C. anglicus and Malt (1982) for Oncaea borealis. Oncaea spp. and Centropages spp. nauplii were assumed to belong to the same species as the observed adults. Other copepod nauplii (normally less than 5\%) were counted but not identified. In each sample, all or ca. 200 nauplii per sample were identified. For samples containing more than 200 nauplii, the species and stage composition were corrected to the total count.

Initially we had difficulty separating N1 and N2 of Oithona nana and O. similis. Therefore, lengths from later identified samples were used to construct size cut-off points for the separation of $O$. similis and $O$. nana stages $\mathrm{N} 1$ and $\mathrm{N} 2$ for the early samples (10 samples). The cut-off points were verified by applying the constructed size limits to the already analyzed data, and then comparing the outcome of the procedure with the numbers resulting from real identifications (Table 1). The same procedure was used to separate uncertain cases, mostly stages N1 and N2, of Microcalanus pusillus and Paracalanus parvus (data not shown). 
Table 1. Oithona nana and O. similis. Verification of the separation of stages N1 and N2. Cross-table comparison of numbers resulting from assigning nauplii to groups based on body length $(x, \mu \mathrm{m})$ with numbers of actually observed identifications based on taxonomic characters (see 'Materials and methods'). The percentage values (in parentheses) represent the fraction of the total observed nauplii of a specific species and stage (each of columns 3 to 6 ) being assigned to a length group (groups defined in column 1). Percentage values sum up to $100 \%$ in the vertical direction, i.e. all observed nauplii of a certain species and stage are assigned to 1 of the 4 possible size groups. For easy comparison the total sums of observed and assigned numbers are indicated in the 2 bottom rows. Gray shading indicates that the assigned group matches the observed group

\begin{tabular}{|c|c|c|c|c|c|}
\hline $\begin{array}{l}\text { Assigned } \\
\text { group }\end{array}$ & $\begin{array}{c}\text { Body } \\
\text { length } \\
(\mu \mathrm{m})\end{array}$ & $\begin{array}{l}\text { Observed } \\
\text { O. nana } \\
\text { N1 }\end{array}$ & $\begin{array}{c}\text { ounts basec } \\
\text { O. nana } \\
\text { N2 }\end{array}$ & $\begin{array}{c}\text { on taxonom } \\
\text { O. similis } \\
\text { N1 }\end{array}$ & $\begin{array}{c}\text { c characters } \\
\text { O. similis } \\
\text { N2 }\end{array}$ \\
\hline O. nana N1 & $65.1-83.7$ & $180(88.7)$ & $27(4.1)$ & $0(0)$ & $0(0)$ \\
\hline O. nana N2 & $83.7-102.3$ & $23(11.3)$ & $621(95.1)$ & $2(1.7)$ & $0(0)$ \\
\hline O. similis N1 & 102.3-120.9 & $0(0)$ & $5(0.8)$ & $94(78.3)$ & $20(11.4)$ \\
\hline O. similis N2 & $120.9-155.0$ & $0(0)$ & $0(0)$ & $24(20)$ & $156(88.6)$ \\
\hline $\begin{array}{l}\sum_{\text {observed }} \\
\sum_{\text {assigned }}\end{array}$ & & $\begin{array}{l}203 \\
207\end{array}$ & $\begin{array}{l}653 \\
646\end{array}$ & $\begin{array}{l}120 \\
119\end{array}$ & $\begin{array}{l}176 \\
180\end{array}$ \\
\hline
\end{tabular}

the relevant species. The model currency is $\mu \mathrm{g} C$, but for several processes the body length $(L)$ is more relevant. We applied published species-specific length-weight relationships, separate for nauplii and copepodids, to switch between length and weight (regressions compiled by Mauchline 1998), and applied a conversion factor of 0.4 $\mu \mathrm{g} \mathrm{C} \mu \mathrm{g}^{-1}$ dry weight (Parsons et al. 1984) when necessary. We assumed that adult copepods allocate all surplus energy to reproduction such that:

$$
b(w, z)=\frac{g(z) \times w_{\text {adult }}}{w_{\text {egg }}}
$$

where $b$ is the number of eggs produced per unit time and $w_{\text {adult }}$ and $W_{\text {egg }}$ are female and egg weights, respectively.

Model. We formulated a habitat selection model based on sub-models of predation risk from visually foraging planktivores (i.e. juvenile sprat and herring that dominate in this area) and zooplankton predators (i.e. ambush copepods), and of temperaturedependent growth rate.

Growth and reproduction: Food, in terms of phytoplankton (chl a) and nauplii, was available in high concentrations (see Fig.1). The mean chl a concentration of $\sim 3 \mu \mathrm{g} \mathrm{l}^{-1}$ at the peak corresponds to $\sim 150 \mu \mathrm{g} \mathrm{C}^{-1}$. Most adult copepods have a maximum or near maximum ingestion at such concentrations, both when feeding on phytoplankton (e.g. Calanus pacificus, Frost 1972; Oithona nana, Lampitt \& Gamble 1982; Acartia tonsa, Saiz \& Kiørboe 1995) and ciliates (e.g. A. tonsa, Saiz \& Kiørboe 1995). Younger developmental stages require less food (reviewed in Mauchline 1998). Given that carbon is also available from nauplii (see Fig. 2) and other microzooplankton (not quantified), as well as from the chl $a$, we assumed that food is plentiful. Therefore, growth $(g)$ is controlled here by temperature $[T(z)]$ at depth $(z)$ only (cf. Huntley \& Lopez 1992). Thus:

$$
g(z)=g_{15} \times Q_{10} \frac{T(z)-15}{10}
$$

where $g_{15}$ is the maximum specific growth rate $\left(\mathrm{g} \mathrm{g}^{-1}\right.$ $\mathrm{s}^{-1}$ ) at $15^{\circ} \mathrm{C}$, and $Q_{10}$ is around 3.0 for calanoids (Huntley \& Lopez 1992). Each species was specified by its egg and adult weight and the weights of intermediate stages were computed assuming isochronal development (e.g. O. similis, Sabatini \& Kiørboe 1994). Kiørboe \& Sabatini (1995) compiled $g_{15}, Q_{10}$, and weights for
Predation risk: Predation risk is a function of predator-prey encounter rates and post-encounter escape probabilities. Volume encounter rate $\left(\beta, \mathrm{cm}^{3}\right.$ predator $^{-1}$ $\mathrm{s}^{-1}$ ) with a predator, be it a fish (f) or a copepod (A), depends on the predator detection distance $(R, \mathrm{~cm})$ and the relative velocity between predator and prey $(\Delta v$, $\mathrm{cm} \mathrm{s}^{-1}$ ) such that:

$$
\beta=\pi R^{2} \Delta v
$$

Ultimately, the reactive distance $R$ is the key to understanding the susceptibility of zooplankton to both visual and tactile predators. In interactions with fish, predator velocity $\left(u_{\mathrm{f}}\right)$ exceeds that of the prey $\left(v_{\mathrm{b}}\right)$, i.e. $u_{\mathrm{f}} \gg v_{\mathrm{b}}$. Thus, $\Delta v$ simplifies to $u_{\mathrm{f}}$ and

$$
\beta_{\mathrm{f}}=q \pi R_{\mathrm{f}}^{2} u_{\mathrm{f}}
$$

where $q$ is the fraction of the cross sectional area of the perceptive field that is efficiently scanned ( 50\%, Rosenthal \& Hempel 1970). For small planktivorous fish, e.g. larvae, prey to predator size ratios $(\lambda)$ typically range from 2 to $8 \%$ (Munk 1995), with smaller prey being ignored or undetected, and larger prey being too evasive to be captured. We let each individual prey be subject to a fish predator of length about $1 / \lambda$ $(=20)$ times the prey's own body length $(L)$. This implies that predators that are larvae or small fishes were considered. The search velocity of the fish is 1 body length $\mathrm{s}^{-1}$, or $L / \lambda \mathrm{s}^{-1}$. Predator visual ability, prey size, prey pigmentation, and light all affect $R_{\mathrm{f}}$ (Aksnes \& Giske 1993, Aksnes \& Utne 1997). If $R_{\mathrm{f}}$ approximates 1 fish body length under light satiated conditions (or $L / \lambda$ ) and light limitation is modeled as suggested by Aksnes \& Utne (1997), then Eq. (3) becomes: 


$$
\beta_{\mathrm{f}}=u_{\mathrm{f}} q \pi\left(\frac{L}{\lambda} \frac{E_{b}}{K_{e}+E_{b}}\right)^{2}
$$

where $K_{e}$ is the light level $\left(5 \mu \mathrm{mol} \mathrm{E} \mathrm{m}{ }^{-2} \mathrm{~s}^{-1}\right.$, Aksnes \& Utne 1997) $R_{\mathrm{f}}$ is half of its light satiated value (i.e. $L / 2 \lambda$ ) and $E_{b}$ is the ambient light. Our choice of $K_{e}$ is representative of fishes adapted to strong light (Aksnes \& Utne 1997). $E_{b}$ depends on depth ( $z$ ) and irradiance at the surface $S(h)$ at any given hour of day $(h)$ such that:

$$
E_{b}(z, h)=S(h) \sum_{0}^{z} \mathrm{e}^{-k(z)}
$$

where the local light attenuation coefficient is a function of chlorophyll a concentration [ $\Psi(\mathrm{z})]$ (see Fig. 1E,F) (Riley 1956):

$$
k(z)=0.14+0.054 \psi(z)^{\frac{2}{3}}+0.0088 \psi(z)
$$

The solar irradiance at the surface was modeled as a function of $h$ from the measured light level at midday (see Rosland \& Giske 1994).

We assumed that all encounters with fish are lethal. In summary, the rate of clearance by fish increases exponentially with prey body size, decreases nonlinearly with depth and varies over the diel light cycle. Because both the prey predator size-ratio and capture success are constant, the predation rate from fish $\mu_{\mathrm{f}}\left(z_{\text {, }}\right.$ $L, h)$ is a function of total fish concentration $\left(C_{\mathrm{f}}\right)$, prey length, depth and time of the day:

$$
\mu_{\mathrm{f}}(z, L, h)=\beta_{\mathrm{f}}(z, L, h) C_{\mathrm{f}}
$$

We did not sample the fish community during the cruise, but evaluated the sensitivity of our predictions to different levels of $C_{\mathrm{f}}$ assuming that $C_{\mathrm{f}}$ is constant over depth and prey size.

As with fish, volume encounter with other copepods $\beta_{\mathrm{A}}$ is given by Eq. (1). Nauplii and copepodids typically engage in 3 types of behavior; sinking, swimming, and jumping, here denoted by subscript $s, \mathrm{w}$, and $\mathrm{j}$ respectively (e.g. Tiselius \& Jonsson 1990, Titelman \& Kiørboe 2003a). In addition, behavior is highly species- and stage-specific, also for nauplii (Titelman \& Kiørboe 2003a). Because $R_{\mathrm{A}}$ strongly depends on prey motility behavior, we calculated $R_{\mathrm{A}}$, and $\Delta v$ using behaviorspecific speeds for each of the various species and stages. For each prey species and stage we thus obtained volume encounter kernels for each of these 3 behaviors; $\beta_{\mathrm{As}} \beta_{\mathrm{Aw}}$ and $\beta_{\mathrm{Aj}}$ (Titelman \& Kiørboe 2003b). Many copepods are capable of switching between an ambush and a feeding current or a cruising foraging strategy (e.g. Jonsson \& Tiselius 1990, Tiselius \& Jonsson 1990). We here assumed that all copepod predators are ambush foragers. This assumption generates conservative volume encounter rates because it minimizes $\Delta v$. A copepod detects a (spherical) prey of radius $a_{1}$ or $0.5 L$, sinking passively with a speed $v_{\mathrm{bs}}$ at a distance $R_{\mathrm{As}}$ :

$$
R_{\mathrm{As}}=\frac{K v_{\mathrm{bs}} \mathrm{a}}{u^{*}}
$$

where $u^{*}$ is the critical velocity required for the predator to respond, and $K$ is a non-dimensional parameter of $\sim 1$ (Kiørboe \& Visser 1999). The distance at which a self-propelled prey with velocity $v_{\mathrm{b}}$ can be detected is better approximated as:

$$
R_{\mathrm{Aw} / \mathrm{j}}=\left(\left|\frac{3 \pi v_{\mathrm{b}} a^{2}[1+3 \cos (2 \theta)]}{2 u^{*}}\right|\right)^{0.5}
$$

where $\theta$ is the detection angle (Svensen \& Kiørboe 2000, Visser 2001) and $v_{\mathrm{b}}$ is jumping $\left(V_{\mathrm{bj}}\right)$ or swimming $\left(v_{\mathrm{bw}}\right)$ velocity. We always set $\theta=\pi / 2$. Because Eq. (2) assumes that $R_{\mathrm{A}}$ is measured from the center of the detection sphere, we corrected by adding half a predator width to the estimates. For swimming and jumping prey we assumed random arrival of encounters, $\Delta v=\left(v_{\mathrm{b}}^{2}+u_{\mathrm{A}}^{2}\right)^{0.5}$, and for sinking prey we assumed differential settling, $\Delta v_{\mathrm{s}}=\left|v_{\mathrm{bs}}-u_{\mathrm{A}}\right|$, where $u_{\mathrm{A}}$ is predator sinking speed. The total predator volume encounter rate is now computed as:

$$
\beta_{\mathrm{A}}=\beta_{\mathrm{s}} \tau_{\mathrm{s}}+\beta_{\mathrm{j}} \tau_{\mathrm{j}}+\beta_{\mathrm{w}} \tau_{\mathrm{w}}
$$

where $\tau_{\mathrm{s}} \tau_{\mathrm{j}}$, and $\tau_{\mathrm{w}}$ are the time fractions spent sinking, jumping and swimming, respectively (Titelman \& Kiørboe 2003b).

Once encountered, prey may escape. We modeled the prey escape probability $P_{\mathrm{e}}$ as an empirical (sigmoid) function of prey $(L)$ to predator $\left(L_{\mathrm{A}}\right)$ length ratio:

$$
P_{\mathrm{e}}\left(L_{\mathrm{A}}, L\right)=\left[1+\exp \left(-\frac{\left(L / L_{\mathrm{A}}\right)-k_{h}}{b}\right)\right]^{-1}
$$

where $k_{h}$ is the prey-predator size ratio where $P_{\mathrm{e}}$ equals 0.5 , and $b$ is a shape-parameter. The parameters were adopted from the size-dependent capture probabilities reported in Caparroy et al. (2000, their Fig. 4), yielding $k_{h}=0.2$ and $b=0.05$.

So far, the predation risk from copepodids depends on prey motility and prey and predator size. To evaluate the spatial profile of mortality risk at our field station, we first needed to summarize the size-structured concentrations of predators $C_{\mathrm{A}}\left(z_{1} L_{\mathrm{A}}\right)$ at each depth. We averaged the observed copepodid concentrations in length intervals $\left(L_{\mathrm{A}}\right)$ of $20 \mu \mathrm{m}$ at each sampling depth, and used linear interpolation to get a concentration for each meter in the water column. Then, the rate of deadly encounters with copepod predators, $\mu_{\mathrm{A}}(z, L)$ $\left(\mathrm{h}^{-1}\right)$, for a prey of length $L$ at depth $z$ becomes a sizedependent function of volume encounter, predator concentration and escape:

$$
\mu_{\mathrm{A}}(z, L)=\sum_{L_{\mathrm{A}}} \beta_{\mathrm{A}}\left(L_{\mathrm{A}}, L\right) C_{\mathrm{A}}\left(L_{\mathrm{A}}, z\right)\left[1-P_{\mathrm{e}}\left(L_{\mathrm{A}}, L\right)\right]
$$

Species-specific motility parameters and behavioral time budgets are generally only available for adult fe- 
males (e.g. Tiselius \& Jonsson 1990) and some stages of nauplii (e.g. Titelman \& Kiørboe 2003a) (see Fig. 5). We therefore converted speeds to body lengths (bl) $\mathrm{s}^{-1}$ and applied them to 3 stage groups for each species; N1-N2, N3-N6, and C1-C6. For nauplii, we approximated sinking speeds with the relationship $v=1.68 L^{1.38}$ (Titelman \& Kiørboe 2003a) and for copepods with $v=0.88 L^{1.38}\left(\mathrm{R}^{2}=\right.$ 0.47, $\mathrm{n}=6$, fitted from data in Tiselius \& Jonsson 1990, Svensen \& Kiørboe 2000), where units of $v$ and $L$ are $\mathrm{mm}$ $\mathrm{s}^{-1}$ and $\mathrm{mm}$, respectively.

Fitness and optimal depth selection: We applied a dynamic programming model (Mangel \& Clark 1988) to compute the optimal habitats for each stage over time. We assumed that animals are free to move $1 \mathrm{~m}$ up or down every hour, and select habitats such that the number of offspring produced over the lifetime is maximized. This implies that an organism in any state $W$ maximizes its expected future reproductive value $V(w, h, H)$ from time $h$ to the time horizon $H$ by picking the optimal habitat $z^{*}$. Our general dynamic programming (sensu Mangel \& Clark 1988) equation is:

$$
\begin{aligned}
& V(w, h, H)=\max _{z}\left\{b(w, z)+\exp \left[-\mu_{\mathrm{f}}\left(z, L_{w}, h\right)-\right.\right. \\
& \left.\left.\mu_{\mathrm{A}}\left(z, L_{w}\right)\right] \times V[w(1+g(z)), h+1, H]\right\}
\end{aligned}
$$

The terms $b(w, z), g(z), \mu_{\mathrm{f}}\left(z, L_{w}, h\right)$ and $\mu_{\mathrm{A}}\left(z, L_{w}\right)$ are the contributions at time $h$ to fitness from reproduction, growth and fish and copepod predation, respectively.

The model was run over at least $30 \mathrm{~d}$ in time intervals of $1 \mathrm{~h}$, always using the environment recorded in the field program. 'Terminal effects' are behaviors that maximize the fitness criterion specified at $H$ rather than the reproductive value (Mangel \& Clark 1988). We set terminal fitness $V(w, H, H)=w_{\text {, }}$ and always checked that $H$ was sufficiently large to avoid any influence from this assumption.

\section{RESULTS}

\section{Field observations}

\section{Environmental conditions}

Hydrographical conditions and zooplankton distributions were largely invariant during the cruise (Fig. 1A-F). We therefore averaged the profiles across sampling times, i.e. both days, to get environmental forcing for the model, including the size-structured copepodid predator field (Figs. 1J \& 2). We considered 2 temperature scenarios; viz. one obtained from averaging the first 10 profiles, i.e. until 17:30 h on Day 2, and one obtained from averaging the remaining 4 profiles, i.e. from 21:30 h Day 2 (Fig. 1A,B,G).

\section{Zooplankton distribution patterns}

The water column was strongly stratified in terms of zooplankton abundance, with maximum at the less saline surface, minimum at 25 to $30 \mathrm{~m}$ and increasing concentrations towards the bottom (Figs. 1C-F \& 3). Concentrations reached $\sim 220$ and 70 ind. $1^{-1}$ for nauplii and copepodids respectively. The small cyclopoids Oithona nana and Oithona similis dominated numerically, Oithona nana being most abundant with concentrations up to $40 \mathrm{l}^{-1}$ for individual nauplius stages and 10 adult females $\mathrm{l}^{-1}$ (Figs. 3 \& 4). Most calanoid nauplii were located close to the surface, while Microcalanus pusillus, Oncaea borealis and Microsetella norvegica were found towards the bottom (Figs. $3 \& 5$ ). Nauplii of Oithona similis and Pseudocalanus elongatus had an intermediate distribution (Figs. 3 \& 5). Copepodid distribution varied more. Generally, most calanoids concentrated around the deeper pycnocline, the oithonids higher in the water column, and Microcalanus pusillus, Oncaea borealis, and Microsetella norvegica in deeper waters (Figs. $3 \& 5$ ).

Two general features characterized the distribution patterns. First, most species exhibited ontogenetic habitat shifts, with nauplii near the surface and copepodids deeper in the water column (Fig. 5). The calanoid N1 were generally more widely distributed over depth than N2 to 6 (Fig. 5). Curiously, the later copepodid stages of Oithona nana were found in 2 distinct layers, one near the surface and one at depth, while most of the females were found in the surface layer (Fig. 4). Although O. similis concentrations peaked near the surface, the distribution was not as confined to this layer as that of $O$. nana (Figs. $3 \& 5$ ).

Secondly, we could not recognize any patterns of diel vertical migration (DVM) in any stage or species, even when pooling day and night samples separately (cf. Oithona nana, Fig. 4, others not shown). However, because of the high resolution of the data, small sampling volumes, and thus low specific counts, a thorough analysis was only possible for O. nana (Fig. 4). We applied the model to examine factors involved in governing the (lack of) temporal dynamics in the observed distributions, focusing mainly on the nauplii and on the dominating small O. nana.

\section{Model predictions}

We computed optimal ontogenetic distribution patterns for different predator situations; (1) copepods only, (2) fish only, and (3) a combination of fish and copepod predation (Fig. 5), at different levels of $C_{\mathrm{f}}$ (Fig. 6). When including both fish and copepod predation, the model generally predicts an ontogenetic migration reasonably 

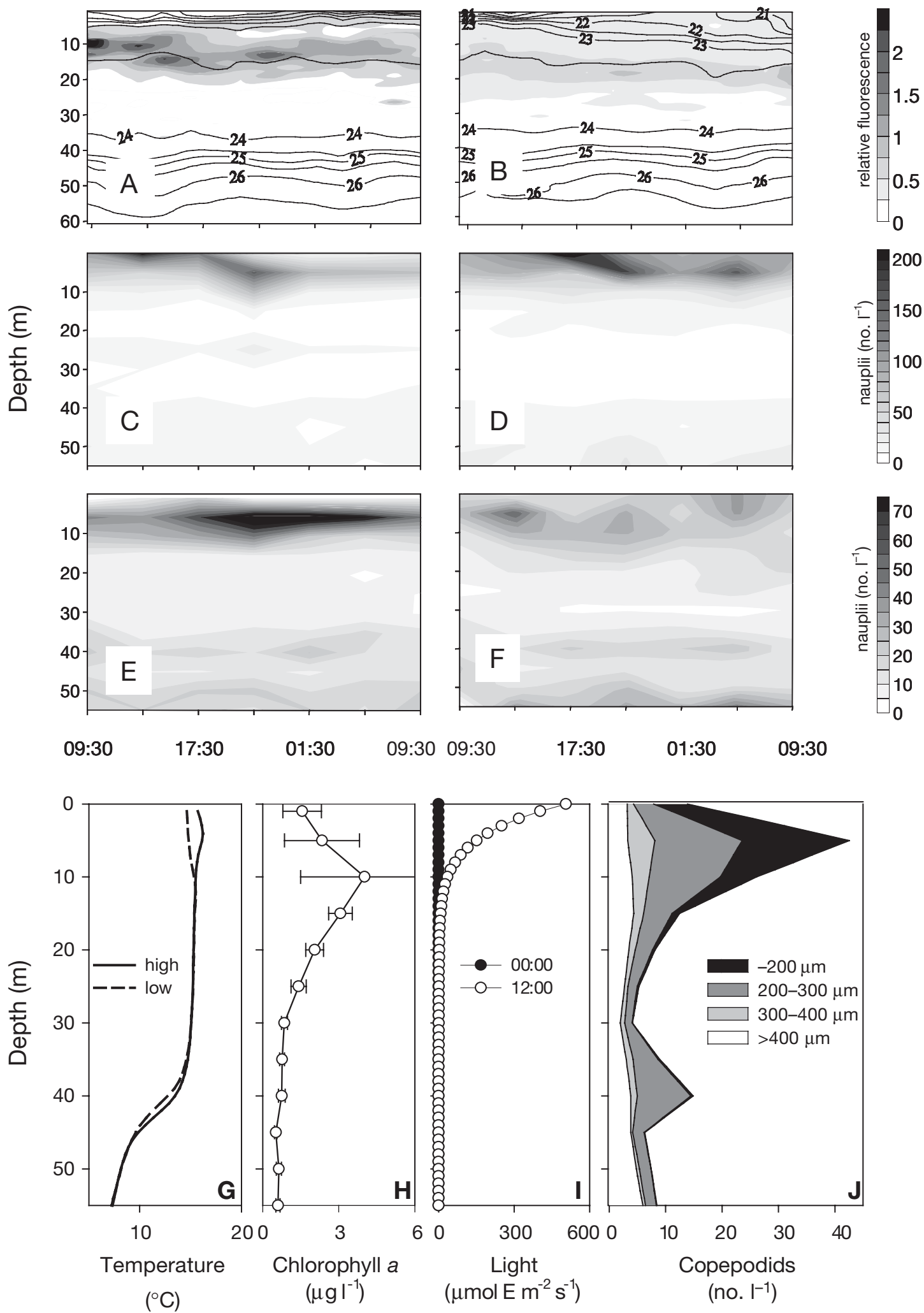

Fig. 1. Environmental forcing and model inputs. $(A, B)$ Isolines of density $\left(\sigma_{t}\right)$, and shadings of relative fluorescence, $(C, D)$ total counts of nauplii and $(\mathrm{E}, \mathrm{F})$ copepodids. (A-F) Left hand panels represent Day 1, and right hand panels Day 2. (G-J) Vertical profiles of model inputs. (G) Temperature. The high $T$ profile is the average from 09:30 h Day 1 to 17:30 h Day 2, and the low $T$ the average of the remaining profiles. (H) Chlorophyll $a_{1}(\mathrm{I})$ light, $(\mathrm{J})$ copepodid predator field, here depicted in groups based on lengths in $10 \mu \mathrm{m}$ intervals 


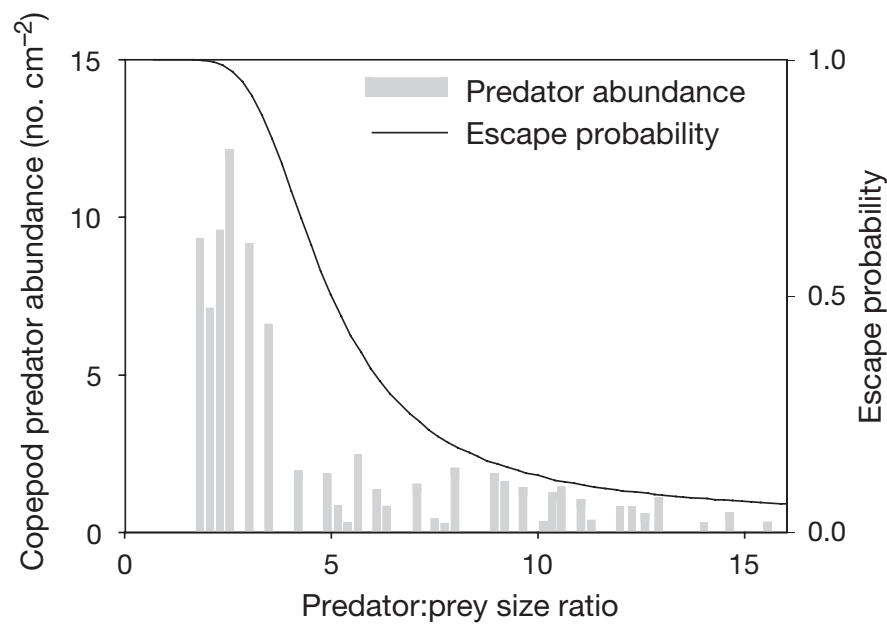

Fig. 2. Oithona nana. The depth integrated copepod predator field (bars) and the corresponding escape probability (line) of an N3 $O$. nana (length $\sim 0.01 \mathrm{~cm}$ ). Bars represent size-specific concentration of predators in the whole water column. Sizes are expressed relative to that of the $O$. nana N3. Probability of escape for the same nauplius is computed according to Eq. (11). The smallest predators (2 to 4 times the length of an N3) are the copepodid stages of $O$. nana and $O$. similis

similar to that observed (Fig. 5). Without risk of fish predation most species remain in the surface layer throughout the ontogeny (Fig. 5). However, some of the younger nauplii (e.g. Temora spp.) are at high risk from the small Oithona copepodids in the surface layer and may thus benefit from a deeper distribution, also in the absence of fish predators (Fig. 5).

The tendency of larger plankters to remain in the surface layer increases with decreasing fish abundance (Figs. $5 \& 6$ ). Similarly, small prey that are relatively more exposed to copepod predators, i.e. nauplii that jump and sink at high frequencies with a noisy motility pattern (e.g. Acartia spp.), require comparatively higher fish concentrations to leave the surface than do silent cruisers (e.g. late Centropages spp.) and cyclopoid nauplii that only jump 1 to 2 times $\mathrm{min}^{-1}$ (Fig. 6). Hydrodynamic conspicuousness also increases with size (Eqs. 9 \& 10), and therefore smaller nauplii may at times benefit from being deeper in the water column than larger nauplii (e.g. Temora spp., Fig. 6). The relative risk from fish and copepod predators thus depends on prey behavior (Fig. 6). Similarly sized nauplii may therefore benefit from different depth distributions, despite similar growth profiles (Figs. 5, 6 \& 7).

The model best matches the field observations for those species where an adequate description of behavior is available for all size groups (e.g. Oithona, Acartia, Temora, Centropages). Concordant with the observations, the model predicted DVM to be an unprofitable strategy for all nauplii, as well as for oithonid copepodids under the prevailing environmental conditions, even at very high fish concentrations (Oithona nana, Fig. 4, others not shown).

\section{DISCUSSION}

\section{Model structure and process formulations}

Our model differs from other models of optimal distribution patterns in zooplankton by its high content of mechanistic process formulations of predation risk. While several papers have modeled the implications of both fish and invertebrate predation on optimal vertical distributions, few have coupled contemporary predator-prey theory with actual distributions of zooplankton in the field and derived optimal habitat selection over time. De Robertis (2002) considered mechanistic models of visual predation and modeled the timing of vertical migration by allowing euphausiids of different sizes to select depth habitats by minimizing the ratio of mortality and energy gain. Ohman et al. (1983) and Ohman (1990) used life-history theory, estimated mortality and growth rates, and observed diel distributions of predators to evaluate fitness of different migration strategies. Fiksen \& Giske (1995) and Fiksen (1997) modeled non-visual predation risk from an empirical size-dependent function, and showed how the relative contribution to mortality from different predators could shape distribution patterns.

Factors such as physical mixing, buoyancy, or UVradiation may also influence the vertical positioning of zooplankton. Our optimization model ignores these, as well as density-dependent factors, such as 'safety in numbers' or competition for food. Giske et al. (1997) modeled a theoretical ideal free distribution of copepods based on such density-dependent processes. They found that food limitation generates dispersion, and that otherwise predation risk and temperature govern distribution patterns and generate aggregation. In the Gullmarsfjord, food was available in high concentrations (Fig. 1H). Although we cannot rule out the role of aggregation as a predator avoidance strategy, we therefore think that the assumption of no density-dependent intra-species interactions is justified.

Implicit in our approach is the assumption of static predator distributions, i.e. we do not consider any response of predators to prey distributions. If predators relocate depending on prey distributions, and prey act as risk-sensitive foragers, the resulting equilibrium distributions of both predators and prey need to be modeled using game theory (e.g. Iwasa 1982). Similarly, we have ignored potential flexibility in motility patterns in response to altered food, predator, or turbulence regimes. Adjustment of motility pattern poten- 


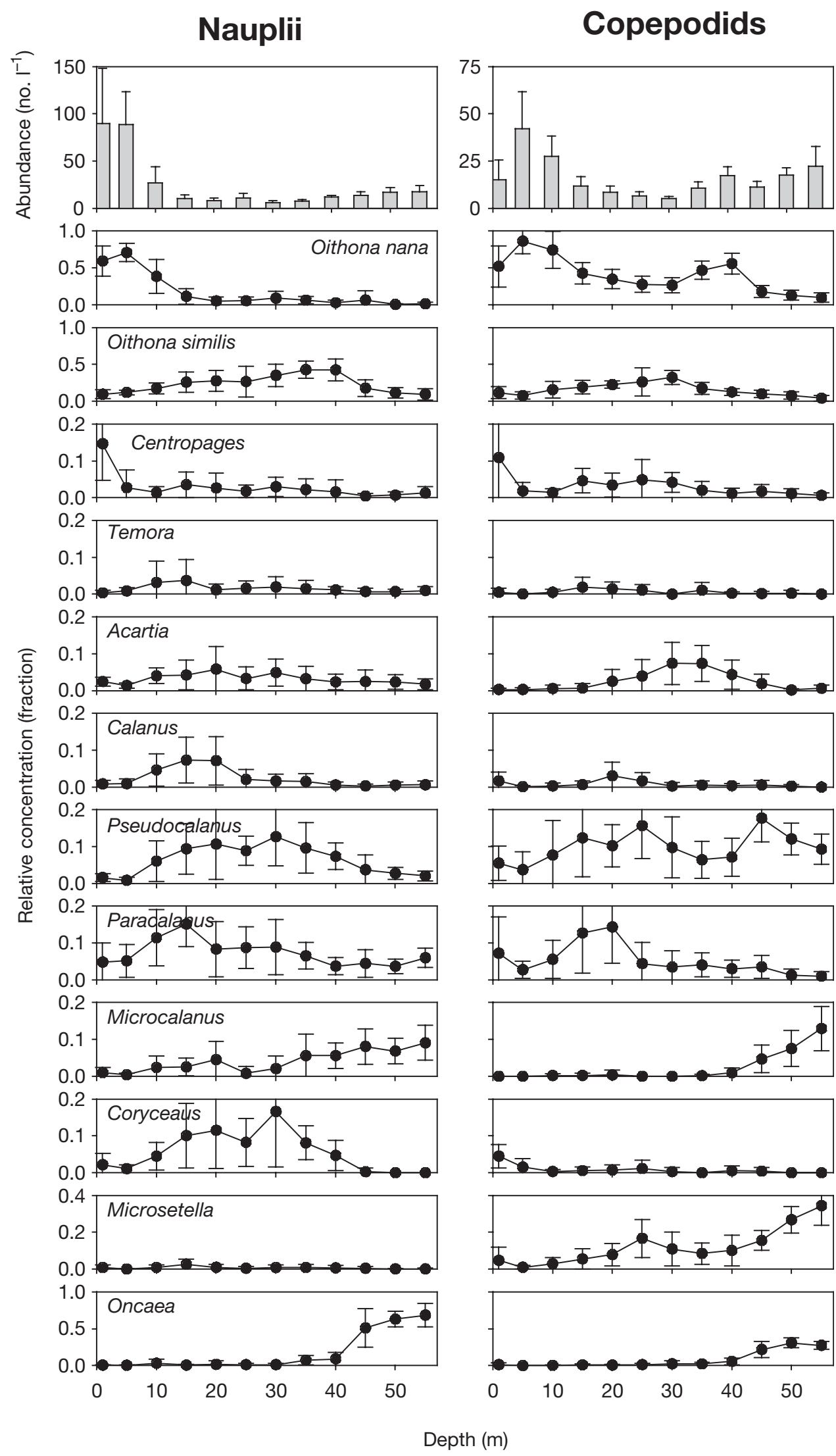

Fig. 3. Vertical profiles of nauplii (left hand panels) and copepodids (right hand panels) of various species. Concentrations are expressed relative to the depth-specific total count of nauplii and copepodids shown in the top panel. Species are indicated in panels and values are averages over all profiles. Error bars are SD 

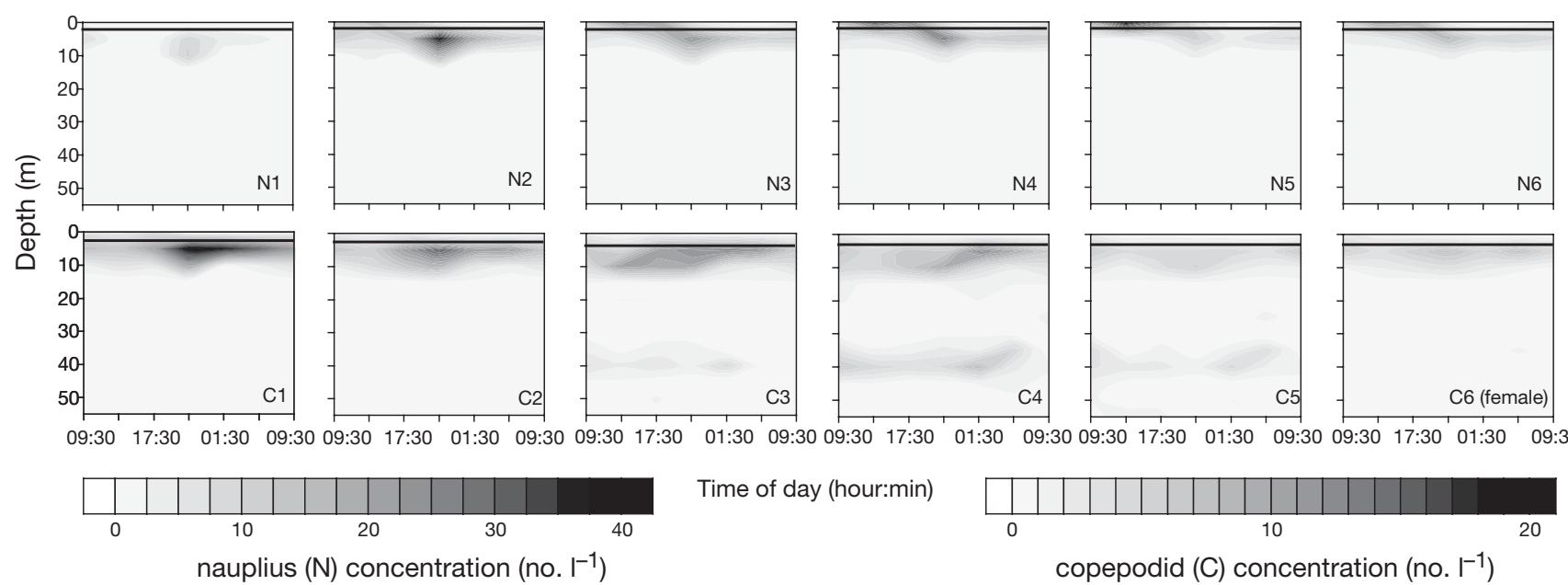

Time of day (hour:min)

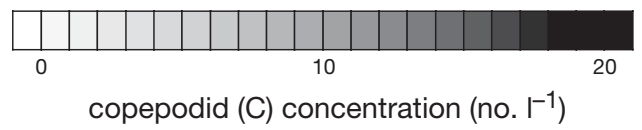

Fig. 4. Oithona nana. Stage-specific distribution over time during Day 1. Results of simulations of optimal depth during the $24 \mathrm{~h}$ period are overlaid (lines). Model assumptions are as in Figs. 5 \& 6. Distributions during Day 2 were similar

tially alters the profitability of the habitats. However, in nauplii, differences in motility between species and stages have larger implications for food and predator encounter than do realistic changes in their respective motility (cf. Titelman \& Kiørboe 2003a,b).

We applied a simple measure of fitness, namely maximization of expected future reproductive output (reproductive value). For Oithona nana, the computed reproductive values are high, from about 5 in N1 to $>30$ in adults (Fig. 7C,D). This implies that the population of $O$. nana was growing rapidly at the time. Alternatively, the model overestimates growth (reproduction) or underestimates mortality rates, or else there are other predators in the system that control population growth.

\section{Distribution patterns of nauplii and Oithona nana}

The vertical profile of risk from copepods and fish at midday for stages N1, N6, and C6 reveal that visual predators contribute little to the mortality risk for Oithona nana (Fig. 8A). Also, the model predicts that the small and silently moving $O$. nana nauplii are comparatively less susceptible to copepod predators than later copepodids (Fig. 8A) or nauplii of other species (Figs. $6 \&$ 8). The minimum predation risk from copepods is at $30 \mathrm{~m}$ for the nauplii and at $5 \mathrm{~m}$ for $\mathrm{C} 6$ (Fig. 8C). This can be interpreted in terms of sizedependent predation risk. The largest copepods, which belong to a size category where risk from fish is significant, were found deeper in the water column than the small and intermediately sized copepods (Fig. 1J). The copepodid stages $(\sim 0.03 \mathrm{~cm})$ of $O$. nana are small enough to be vulnerable to the larger cope- pods (Fig. 8A), and are hence predicted to stay near the surface (Fig. 8C,D). The high concentration of young copepodid stages of $O$. nana around $5 \mathrm{~m}$ (Figs. 3, 4 \& 5) in turn generates a higher risk for small nauplii, explaining the predicted predation minimum at $30 \mathrm{~m}$ (Fig. 8A). The specific growth rate depth profile changes after the shift in temperature (Fig. 8B). When running the model with the initial temperature profile (i.e. high $T$ ), the temperature peak at $5 \mathrm{~m}$ (Fig. 1G) makes this depth the most profitable one for all stages (Fig. 4). However, when forcing the model with the other temperature profile (i. e. low T, Fig. 1G), the deep $(30 \mathrm{~m})$ alternative becomes the most profitable depth for nauplii, while C6 should remain in the surface habitat (Fig. 8D). Contrary to that of the nauplii, the growth of C6 does not decrease sufficiently to offset the benefit of reduced predation risk near the surface. This situation parallels other reports of optimal distributions shaped by size-dependent predation risk. For example, Ohman et al. (1983) found that Pseudocalanus sp. displayed reverse DVM when its invertebrate predators left the surface to avoid fish predation. Although the observed situation in Gullmarsfjord was apparently more static, it may still be interpreted in terms of size-dependent predation chains.

The bimodal distribution of the older copepod stages in Oithona nana is less intuitively understood (Fig. 4). The predicted optimal depth for all stages of $O$. nana is near the surface under the initial temperature regime (Figs. $4 \& 5$ ). The modeled rate of predation by other copepods peaks near $15 \mathrm{~m}$ (Fig. 8A), which is also the depth that $O$. nana avoids (Fig. 4). Given the initial temperature profile (Fig. 1G), the fitness of all stages peaks near the surface, but profiles are relatively flat 

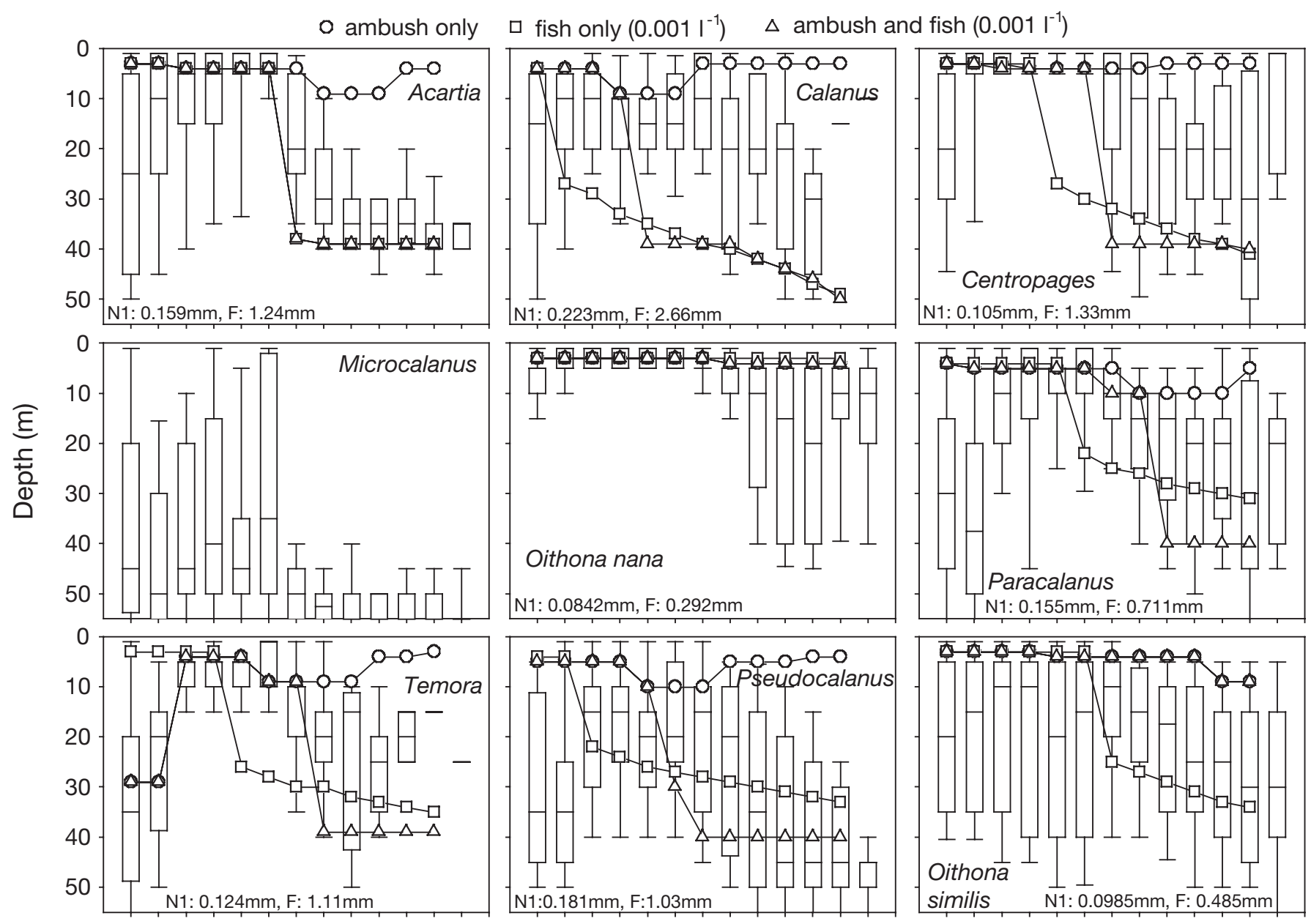

N1 N2 N3N4N5N6C1C2C3C4C5 F M

N1 N2 N3N4 N5 N6 C1 C2 C3C4C5 F M

N1 N2 N3N4 N5 N6 C1 C2 C3C4C5 F M

Fig. 5. Stage-specific depth distribution for Acartia clausii, Calanus finmarchicus, Centropages typicus, Microcalanus pusillus, Oithona nana, Paracalanus parvus, Temora longicornis, Pseudocalanus elongatus and $O$. similis. The box plots were constructed from mean vertical percentage distributions obtained by combining all sampling times. The boxes represent the 25 and $75 \%$, the line the median, the whiskers the 5 and $95 \%$. Overlaid lines are model simulations with different predator regimes: (O) copepods (ambush) only, $(\square)$ fish only, and $(\triangle)$ both copepods and fish. We applied velocities, time budgets and jump frequencies from the literature. For nauplii: Oithona spp (Oithona sp., Paffenhöfer 1993); Pseudocalanus (Landry \& Fagernes 1988); Paracalanus (P. aculeatus, Paffenhöfer et al. 1996); all others (Titelman \& Kiørboe 2003a). For copepods: Oithona spp. (O. similis, Svensen \& Kiørboe 2000); Temora (Van Duren \& Videler 1995); Calanus (Mauchline 1998); all others (Jonsson \& Tiselius 1990, Tiselius \& Jonsson 1990). No behavioral data was available for Microcalanus. We assumed $u^{*}=0.004 \mathrm{~cm} \mathrm{~s}^{-1}\left(O\right.$. similis, Kiørboe \& Visser 1999), $C_{\mathrm{f}}=0.001 \mathrm{l}^{-1}$, and the initial temperature regime (high $T$ ) in all depicted simulations. Note that the bimodal distribution of $O$. nana is disguised in this graph (cf. Fig. 4). Sizes for N1 and females (F) used in the model are indicated in the panels. N = nauplius, C= copepodid, $\mathrm{M}=$ male

with local minima around $20 \mathrm{~m}$ (Fig. 8C). After the disappearance of the sub-surface temperature peak, the optimal depth for stages $<\mathrm{C} 2$ is $30 \mathrm{~m}$ (Fig. 8D). The bimodal distribution pattern could therefore result from frequent switches in the hydrographic regime, and corresponding alterations in optimal habitats over short time spans. Alternatively, the bimodal pattern may result directly from predation. If $O$. nana was initially uniformly or randomly distributed above the thermocline, then predation from large copepods could potentially reduce the concentration of the copepodids substantially at intermediate (15 to $25 \mathrm{~m}$ ) depths. A third possibility is that the feeding habits of $O$. nana may affect its fitness profile and optimal depth. Oithonids are true ambush feeders, feeding predominately on mobile prey and sinking fecal pellets (Sabatini \& Kiørboe 1994, Svensen \& Kiørboe 2000). A deeper distribution of $O$. nana $\mathrm{C} 3$ to $\mathrm{C} 5$, below the bulk of other zooplankton, may secure a steady supply of sinking fecal pellets. Similarly, the phytoplankton composition below the deep chlorophyll maximum might be the motivator of this distribution. Bimodal dis- 

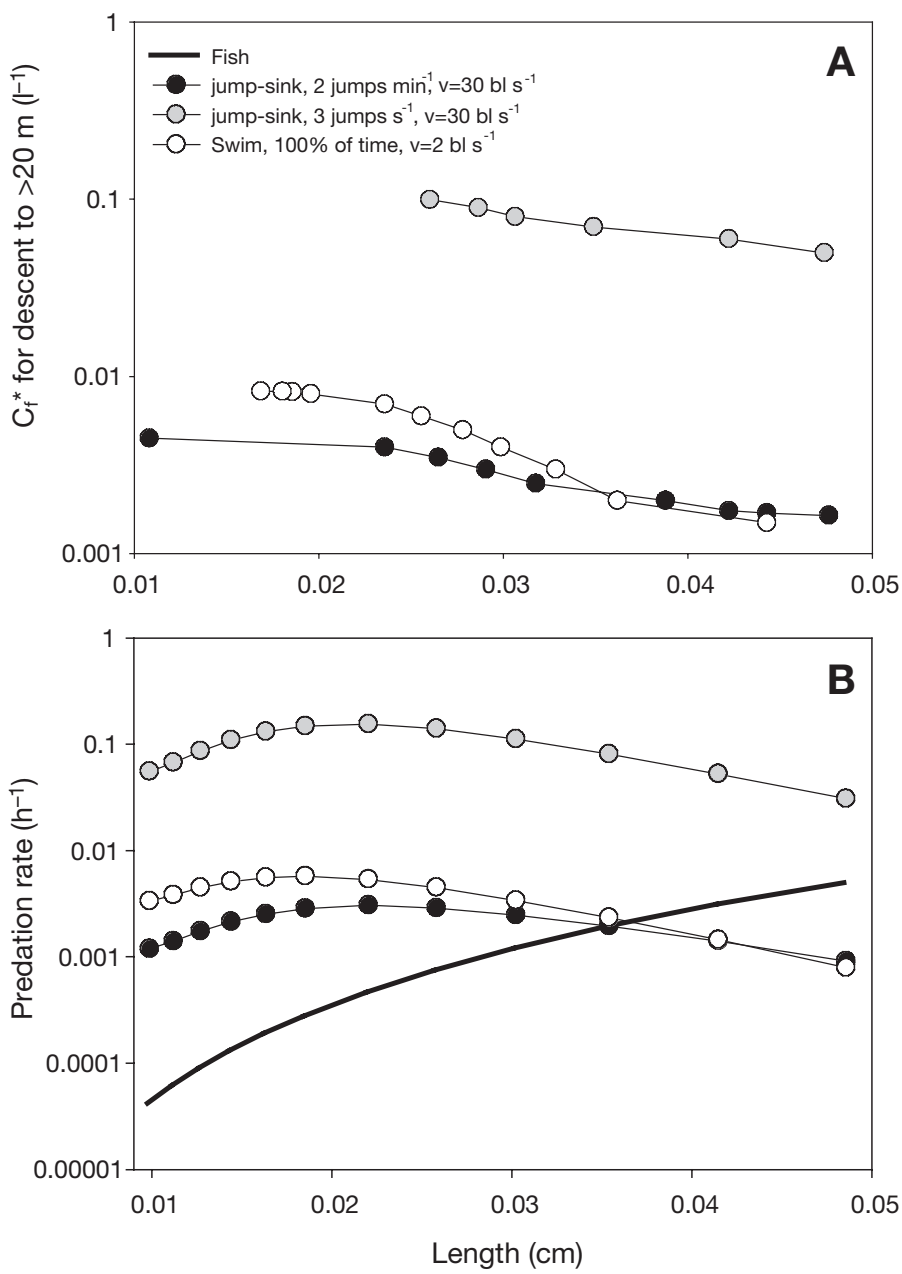

Fig. 6. (A) Critical fish concentration $C_{\mathrm{f}}{ }^{*}$ required for an animal with various motility patterns to descend from the surface habitat to below $20 \mathrm{~m}$ in the water column. Behaviors are representative of the 2 extremes of jump-sink motility in nauplii (i.e. Oithona spp. and late Acartia tonsa) and of a continuous cruiser (e.g. late Temora longicornis) (Titelman \& Kiørboe 2003a). The motility parameters indicated in the panel are applied to an O. similis (Sabatini \& Kiørboe 1994) in order to isolate the impact of motility. Simulations are assuming no ontogenetic changes in motility. All other model parameters are as in Figs. 3, 4 \& 5. Small nauplii of the noisier types cannot descend because their optimal habitat is already deeper (see text). (B) Predation mortality (black line) from fish and copepods for an animal with various motility patterns at $5 \mathrm{~m}$ depth. Temperature and predation regime are as in Fig. 1. Symbols and explanations as in (A)

tributions of copepods in the same developmental stages (Durbin et al. 1995, Hays et al. 2001) may be explained by internal energy conditions, with fatty individuals in safe, deep habitats and less fatty individuals in risky, shallow habitats (Fiksen \& Carlotti 1998). However, O. nana possesses no lipid sac and suffers only a minor predation risk from fish.
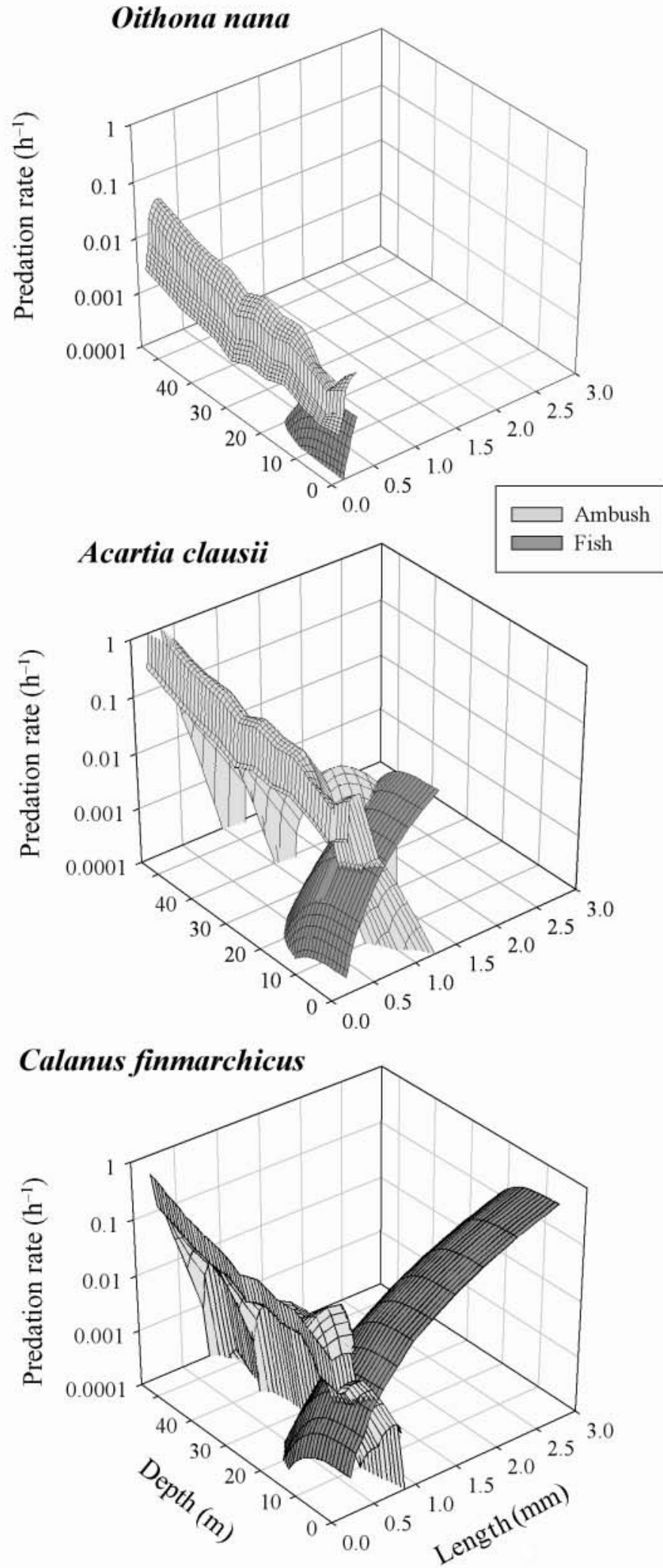

Fig. 7. Oithona nana, Acartia clausii and Calanus finmarchicus. Model predictions of predation rates from fish and copepods at midday. Behavior is as in Fig. 5, all other model parameters and assumptions as in Figs. 4, 5 \& 6 

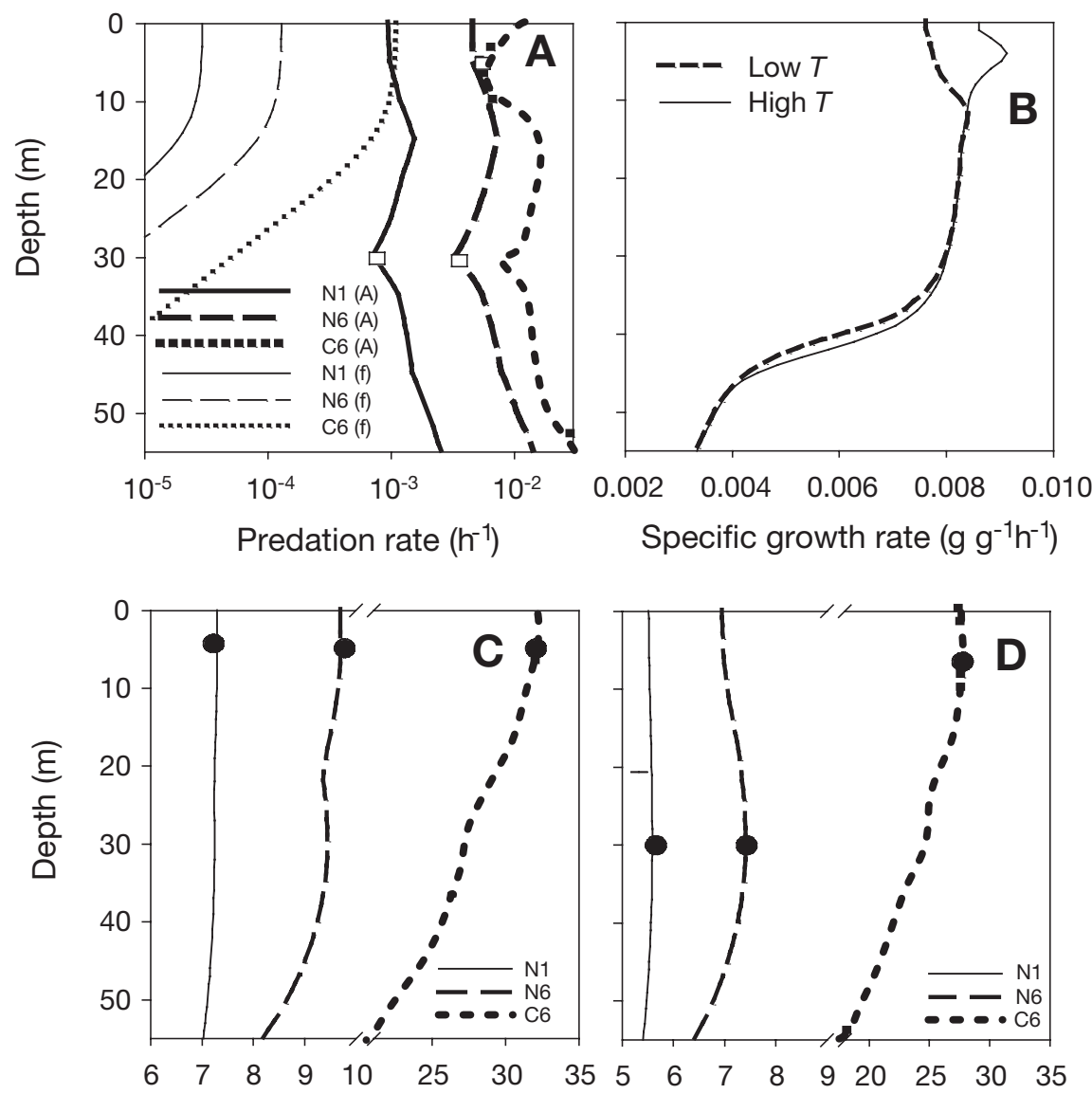

Reproductive value (fitness)

\section{Specific growth rate $\left(\mathrm{g} \mathrm{g}^{-1} \mathrm{~h}^{-1}\right)$}

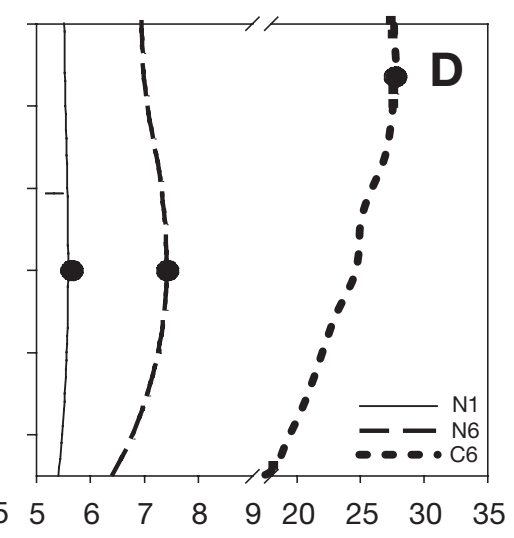

Reproductive value (fitness)
Fig. 8. Oithona nana. Model predictions of vertical profiles of predation, growth, and fitness for stages N1, N6, and C6. (A) Predicted rate of predation from fish (f) and copepods (A). Squares indicate the habitats with the minimum predation risk. (B) Specific growth rates before (high $T$ ) and after (low T) 17:30 h Day 2 (cf. Fig. 1). (C) Reproductive value (Eq. 13) at midday, calculated assuming the high $T$ growth profile and (D) the low $T$ profile. Note that if a copepod is in a sub-optimal depth, it will move towards the optimal habitat $\left(z^{*}\right.$ indicated by in $C$ and $D$ ) at $1 \mathrm{~m} \mathrm{~h}^{-1}$. This behavior will smooth out vertical differences in fitness. In all simulations we assume jump frequency of $2 \mathrm{~min}^{-1}$ for nauplii, $6.9 \mathrm{~min}^{-1}$ for copepodids, jump duration of $0.1 \mathrm{~s}$, jump speed of $\sim 30 \mathrm{bl} \mathrm{s}^{-1}$, and $u^{*}$ of $0.004 \mathrm{~cm} \mathrm{~s}^{-1}$
For nauplii and copepodids of small species such as Oithona spp., the predation risk from copepods dominates over that from fish (Figs. $7 \&$ 8A), and depends strongly on motility (Fig. 6). Hydrodynamically 'noisy', frequently jumping nauplii (e.g. Acartia spp.) experience higher risk of encounter with copepod predators compared to cruising nauplii (e.g. Centropages spp.) or nauplii with a low frequency jump-sink type of motility (Oithona spp.), and therefore require comparatively higher concentrations of fish to descend to deeper waters (Fig. 6).

Changes in the physical environment may also alter distributions. Incze et al. (2001) pointed to behavioral differences between nauplii based on their vertical distributions in response to wind forcing. Some species aggregated at depth during periods of wind and closer to the surface upon cessation of wind, while other species resisted downward mixing and remained at the surface (Incze et al. 2001). Our field data reveal that nauplii of most species reside near the surface (Figs. 1, 3 to 5). Exceptions are Oithona similis, Oncaea borealis, and Coryceaus anglicus nauplii (Figs. $3 \& 5$ ), whose behavior generates very low volume encounter rates with copepod predators (Titelman \& Kiørboe 2003b). These nauplii remain virtually motionless most of the time and relocate occasionally by a brief jump, a few times per minute (Paffenhöfer 1993, Paffenhöfer et al. 1996). Such a motility pattern may allow a higher degree of vertical overlap between nauplii and larger copepodids. This accords with the dispersed distribution patterns of Oithona similis and $C$. anglicus nauplii, and the deeper distribution of Oncaea borealis and Microsetella norvegica nauplii (Figs. $3 \& 5$ ). In addition, copepodids of the latter 2 genera, both of which are egg-bearing, are commonly associated with feeding on marine snow (Green \& Dagg 1997), and may therefore benefit from a deeper distribution.

\section{Lack of DVM}

As pointed out recently in 2 reviews of DVM, it is also possible that a low indication of DVM results from individuals moving asynchronously; feeding in foodrich habitats until their stomachs are filled and then 
returning to safer habitats (Hays 2003, Pearre 2003). However, as we had no way of following individuals, we could not evaluate this hypothesis.

The weak gradient in temperature and growth opportunities (Fig. 8B) partially explains the general lack of DVM that we observed (Oithona nana, Fig. 4). This means that the trade-off between growth and predation risk is weak or absent, such that an animal can move to a deeper, safer habitat without losing much in terms of growth. Another factor that limits the profitability of both normal and inverse DVM in situations such as the one presented here is the static distribution and relatively high concentrations of larger copepodids at intermediate depths (Fig. 1J). Nauplii and small copepodids, like O. nana, would have to pass through a danger zone to migrate between shallow and deeper habitats (Fig. 8A). Jellyfish, chaetognaths and other zooplankton predators, which were not sampled here, may similarly constitute layers of danger.

Migration requires increased cruising speeds or jump frequencies, which leads to much higher risk of being detected and encountered by copepods or other rheotactic predators (Kiørboe et al. 1999, Titelman 2001, Saito \& Kiørboe 2001). Thus, moving through a zone with high predator densities may not be strategicdespite potential benefits on the other side. We therefore suggest that sometimes, and especially if you are small or hydrodynamically inconspicuous to begin with, it is better to remain calm and stay where you are.

\section{Summary and conclusions: influence of motility on distributions}

We have tried to bridge the traditional approaches of descriptive field work and theoretical modeling to examine the vertical distribution and habitat selection of copepod developmental stages. Naturally, distributions of animals result from trade-offs between eating and growing on the one hand, and avoiding being eaten on the other. Despite the limitations of both the field sampling and the model, our results suggest that the distribution of small copepods, especially the nauplii and small species such as Oithona spp., differs from that of the better studied large species and later life history stages. Nauplii and small oithonids are less sensitive to visual predators and more sensitive to invertebrate predators such as larger copepods. While the relative sensitivity to fish predators increases with size, the risk of getting killed by larger copepods is, in addition to size, very sensitive to motility (our Fig. 6B, Titelman \& Kiørboe 2003b). One may therefore expect that small nauplii and copepodids adjust their motility and distribution in relation to non-visual predators. For the nauplii, which are generally most sensitive to copepod predation, one may further expect that the relatively silent motility types, which spend most of their time motionless (e.g. Oithona spp. and Oncaea spp.) or slowly swimming (e.g. N3 to N6 Temora spp., Centropages spp.) can handle more overlap with predators, than larger (late Calanus spp. nauplii) or faster moving hop-sink types (e.g. N1 to N6 Acartia spp.), which generate strong hydrodynamic signals. Albeit that factors such as food layers, density stratification and advection all interplay to determine the distribution of plankton, we suggest that individual behavior may be an important determinant of a zooplankter's optimal depth location, mediated by its effects on the relative susceptibility to functionally different predators such as visually hunting fish or rheotactic copepods. (see also Fiksen et al. in press)

Acknowledgements. We thank T. Kiørboe, P. Tiselius, A. Visser, B. Liljebladh and the crew of RV 'Arne Tiselius' for helping with data collection on the cruise, M. Andersen and T. Bintzer for laboratory assistance, and F. Ferrarri for advising on Oithona taxonomy and for suggesting reference literature for the identification of Coryceaus and Oncaea nauplii. Comments from T. Kiørboe, P. Jonsson and 3 referees improved the manuscript. Most of the practical work was carried out at the Danish Institute for Fisheries Research, Charlottenlund, Denmark. This study was supported by grants from the EU (TMR Marie Curie PhD Fellowship FMBICT972833) and from the University of Bergen (EU-BATMARE fellowship EVK3-CT-2000-57129) to J.T., and from the Research Council of Norway, NRC (133562/120) to Ø.F.

\section{LITERATURE CITED}

Aksnes DL, Giske J (1993) A theoretical-model of aquatic visual feeding. Ecol Model 67:233-250

Aksnes DL, Utne ACW (1997) A revised model of visual range in fish. Sarsia 82:137-147

Brooks JL, Dodson SI (1965) Predation body size and composition of plankton. Science 150:28

Caparroy P, Thygesen UH, Visser, AW (2000) Modelling the attack success of planktonic predators: patterns and mechanisms of prey size selectivity. J Plankton Res 22: $1871-1900$

Clark CW (1994) Antipredator behavior and the assetprotection principle. Behav Ecol 5:159-170

De Robertis A (2002) Size-dependent visual predation risk and the timing of vertical migration: an optimization model. Limnol Oceanogr 47:925-933

De Robertis A, Jaffe JS, Ohman MD (2000) Size-dependent visual predation risk and the timing of vertical migration in zooplankton. Limnol Oceanogr 45:1838-1844

Durbin EG, Gilman SL, Campbell RG, Durbin AG (1995) Abundance, biomass, vertical migration and estimated development rate of the copepod Calanus finmarchicus in the southern Gulf of Maine during late spring. Cont Shelf Res 15:571-591

Durbin EG, Garrahan PR, Casas MC (2000) Depth distribution of Calanus finmarchicus nauplii on the Georges Bank during 1995 and 1996. ICES J Mar Sci 57:1686-1693 
Fiksen Ø (1997) Allocation patterns and diel vertical migration: Modeling the optimal Daphnia. Ecology 78:1446-1456

Fiksen Ø, Carlotti F (1998) A model of optimal life history and diel vertical migration in Calanus finmarchicus. Sarsia 83: 129-147

Fiksen Ø, Giske J (1995) Vertical-distribution and populationdynamics of copepods by dynamic optimization. ICES J Mar Sci 52:483-503

Fiksen $\varnothing$, Edliassen S, Titelman J (in press) Multiple predators in the pelagic: modelling behavioral cascades. J Anim Ecol

Frost BW (1972) Effects of size and concentration of food particles on feeding behavior of marine planktonic copepod Calanus pacificus. Limnol Oceanogr 17:805-815

Frost BW, Bollens SM (1992) Variability of diel vertical migration in the marine planktonic copepod Pseudocalanus newmani in relation to its predators. Can J Fish Aquat Sci 49:1137-1141

Gibbons SG, Ogilvie HS (1933) The development stages of Oithona helgolandica and Oithona spinirostris with a note on the occurrence of body spines in cyclopoid nauplii. J Mar Biol Assoc UK NS18:529-550

Gibson VR, Grice GD (1978) Developmental stages of a species of Corycaeus (Copepoda-Cyclopoida) from Saanich Inlet, British-Columbia. Can J Zool 56:66-74

Giske J, Rosland R, Berntsen J, Fiksen Ø (1997) Ideal free distribution of copepods under predation risk. Ecol Model 95: 45-59

Green EP, Dagg MJ (1997) Mesozooplankton associations with medium to large marine snow aggregates in the northern Gulf of Mexico. J Plankton Res 19:435-447

Haq SM (1965) The larval development of Oithona nana. J Zool 146:555-566

Hays GC (2003) A review of the adaptive significance and ecosystem consequences of zooplankton diel vertical migrations. Hydrobiologia 503:163-170

Hays GC, Kennedy H, Frost BW (2001) Individual variability in diel vertical migration of a marine copepod: Why some individuals remain at depth when others migrate. Limnol Oceanogr 46:2050-2054

Huntley ME, Lopez MDG (1992) Temperature-dependent production of marine copepods - a global synthesis. Am Nat 140:201-242

Incze LS, Hebert D, Wolff N, Oakey N, Dye D (2001) Changes in copepod distributions associated with increased turbulence from wind stress. Mar Ecol Prog Ser 213:229-240

Iwasa Y (1982) Vertical migration of zooplankton-a game between predator and prey. Am Nat 120:171-180

Jonsson PR, Tiselius P (1990) Feeding behaviour, prey detection and capture efficiency of the copepod Acartia tonsa feeding on planktonic ciliates. Mar Ecol Prog Ser 60:35-44

Kiørboe T, Sabatini M (1995) Scaling of fecundity, growth and development in marine planktonic copepods. Mar Ecol Prog Ser 120:285-298

Kiørboe T, Visser AW (1999) Predator and prey perception in copepods due to hydromechanical signals. Mar Ecol Prog Ser 179:81-95

Kiørboe T, Saiz E, Visser A (1999) Hydrodynamic signal perception in the copepod Acartia tonsa. Mar Ecol Prog Ser 179:97-111

Lagadeuc Y, Boule M, Dodson JJ (1997) Effect of vertical mixing on the vertical distribution of copepods in coastal waters. J Plankton Res 19:1183-1204

Lampitt RS, Gamble JC (1982) Diet and respiration of the small planktonic marine copepod Oithona nana. Mar Biol 66:185-190

Landry MR, Fagerness VL (1988) Behavioral and morpholog- ical influences on predatory interactions among marine copepods. Bull Mar Sci 43.509-529

Loose CJ, Dawidowicz P (1994) Trade-offs in diel vertical migration by zooplankton - the costs of predator avoidance. Ecology 75:2255-2263

Lovegrove T (1956) Copepod nauplii (II). Cons Int Explor Mer Zooplankton Sheet 63

Malt SJ (1982) Developmental stages of Oncaea media Giesbrecht, 1891 and Oncaea subtilis Giesbrecht, 1892. Bull Br Mus (Nat Hist) Zool 43:129-151

Mangel M, Clark CW (1988) Dynamic modeling in behavioral ecology. Princeton University Press, Princeton, NJ

Mauchline J (1998) The biology of calanoid copepods. Adv Mar Biol Vol 33. Academic Press, San Diego

Munk P (1995) Foraging behaviour of larval cod (Gadus morhua) influenced by prey density and hunger. Mar Biol 122:205-212

Oberg M (1906) Die Metamorphose der Plankton-Copepoden der Kieler Bucht. Wiss Meeresunter 9:37-175

Ogilvie HS (1953) Copepod nauplii (I). Cons Int Explor Mer Zooplankton Sheet 50

Ohman MD (1990) The demographic benefits of diel vertical migration by zooplankton. Ecol Monogr 60:257-281

Ohman MD, Frost BW, Cohen EB (1983) Reverse diel vertical migration - an escape from invertebrate predators. Science 220:1404-1407

Paffenhöfer GA (1993) On the ecology of marine cyclopoid copepods (Crustacea, Copepoda). J Plankton Res 15: $37-55$

Paffenhöfer GA, Strickler JR, Lewis KD, Richman S (1996) Motion behavior of early copepodid stages of marine and planktonic copepods. J Plankton Res 18:1699-1715

Parsons TR, Takahashi M, Hargrave B (1984) Biological oceanographic process, 3rd edn. Pergamon Press, Oxford

Pearre S (2003) Eat and run? The hunger/satiation hypothesis in vertical migration: history, evidence and consequences. Biol Rev Camb Philos Soc 78:1-79

Riley GA (1956) Oceanography of the Long Island Sound 1952-1954. II Physical oceanography. Bull Bingham Oceanogr Collect 15:15-46

Rosenthal H, Hempel G (1970) Experimental studies in feeding and food requirements of herring larvae (Clupea harengus). In: Steele JH (ed) Marine food chains. Oliver \& Boyd, Edinburgh, p 344-364

Rosland R, Giske J (1994) A dynamic optimization model of the diel vertical-distribution of a pelagic planktivorous fish. Prog Oceanogr 34:1-43

Sabatini M, Kiørboe T (1994) Egg production, growth and development of the cyclopoid copepod Oithona similis. J Plankton Res 16:1329-1351

Saito H, Kiørboe T (2001) Feeding rates in the chaetognath Sagitta elegans: effects of prey size, prey swimming behaviour and small-scale turbulence. J Plankton Res 23: 1385-1398

Saiz E, Kiørboe T (1995) Predatory and suspension-feeding of the copepod Acartia tonsa in turbulent environments Mar Ecol Prog Ser 122:147-158

Sell AF, van Keuren D, Madin LP (2001) Predation by omnivorous copepods on early developmental stages of Calanus finmarchicus and Pseudocalanus spp. Limnol Oceanogr 46:953-959

Svensen C, Kiørboe T (2000) Remote prey detection in Oithona similis: hydromechanical versus chemical cues. J Plankton Res 22:1155-1166

Tiselius P, Jonsson PR (1990) Foraging behavior of six calanoid copepods: observations and hydrodynamic analysis. Mar Ecol Prog Ser 66:22-33 
Tiselius $\mathrm{P}$, Jonsson PR, Kaartvedt S, Olsen EM, Jørstad T (1997) Effects of copepod foraging behavior on predation risk: An experimental study of the predatory copepod Pareuchaeta norvegica feeding on Acartia clausi and A. tonsa (Copepoda). Limnol Oceanogr 42:164-170

Titelman J (2001) Swimming and escape behavior of copepod nauplii: implications for predator-prey interactions among copepods. Mar Ecol Prog Ser 213:203-213

Titelman J, Kiørboe T (2003a) Motility of copepod nauplii and implications for food encounter. Mar Ecol Prog Ser 247: 123-135

Editorial responsibility: Otto Kinne (Editor),

Oldendorf/Luhe, Germany
Titelman J, Kiørboe T (2003b) Predator avoidance by nauplii. Mar Ecol Prog Ser 247:137-149

Van Duren LA, Videler JJ (1995) Swimming behavior of developmental stages of the calanoid copepod Temora longicornis at different food concentrations. Mar Ecol Prog Ser 126:153-161

Visser AW (2001) Hydromechanical signals in the plankton. Mar Ecol Prog Ser 222:1-24

Zaret TM, Suffern JS (1976) Vertical migration in zooplankton as a predator avoidance mechanism. Limnol Oceanogr 21: 804-813

Submitted: January 19, 2004; Accepted: August 24, 2004 Proofs received from author(s): December 17, 2004 